\title{
Endoscopic ultrasound-guided drainage of an abdominal abscess using a lumen-apposing metal stent
}

Endoscopic ultrasound (EUS)-guided drainage using a lumen-apposing metal stent (LAMS) is an emerging technique for the treatment of peripancreatic fluid collections, acute cholecystitis in patients unfit for surgery, and malignant distal obstructive jaundice after failed endoscopic retrograde cholangiopancreatography (ERCP) [1]. Moreover, it is a promising treatment for the drainage of mediastinal, liver, and pelvic abscesses [2].

Here, we report the case of a 71-year-old man with advanced cancer of the pancreatic head who had had an uncovered selfexpandable metal stent (SEMS) placed in the common bile duct to ensure biliary drainage. While undergoing chemotherapy, he developed septic shock and a computed tomography (CT) scan revealed a voluminous abdominal abscess $(62 \times 68-\mathrm{mm})$ adjacent to the major gastric curve.

An EUS-guided transgastric drainage was therefore performed. The collection was initially punctured with 19-gauge needle and $5 \mathrm{~mL}$ of purulent liquid was obtained for microbiological evaluation. A 15-mm $\times 10-m m$ LAMS (Hot Axios, Boston Scientific) was then deployed, with subsequent flow of purulent fluid into the gastric lumen ( $\triangleright$ Video 1$)$. A multiresistant Klebsiella aerogenes was isolated from the culture and targeted antimicrobial therapy was started. A CT scan confirmed correct positioning of the stent ( Fig. 1) and his clinical condition rapidly improved.

A follow-up CT scan 10 days later confirmed resolution of the collection. The stent was therefore removed using retrieval forceps and an over-the-scope clip (OTSC 11/6-mm traumatic type; Ovesco, Tübingen, Germany) was placed to close the gastric hole completely. No extraluminal spread of contrast medium was observed. Moderate bleeding was however observed from the phlogistic tissue that was suctioned into OTSC, which stopped

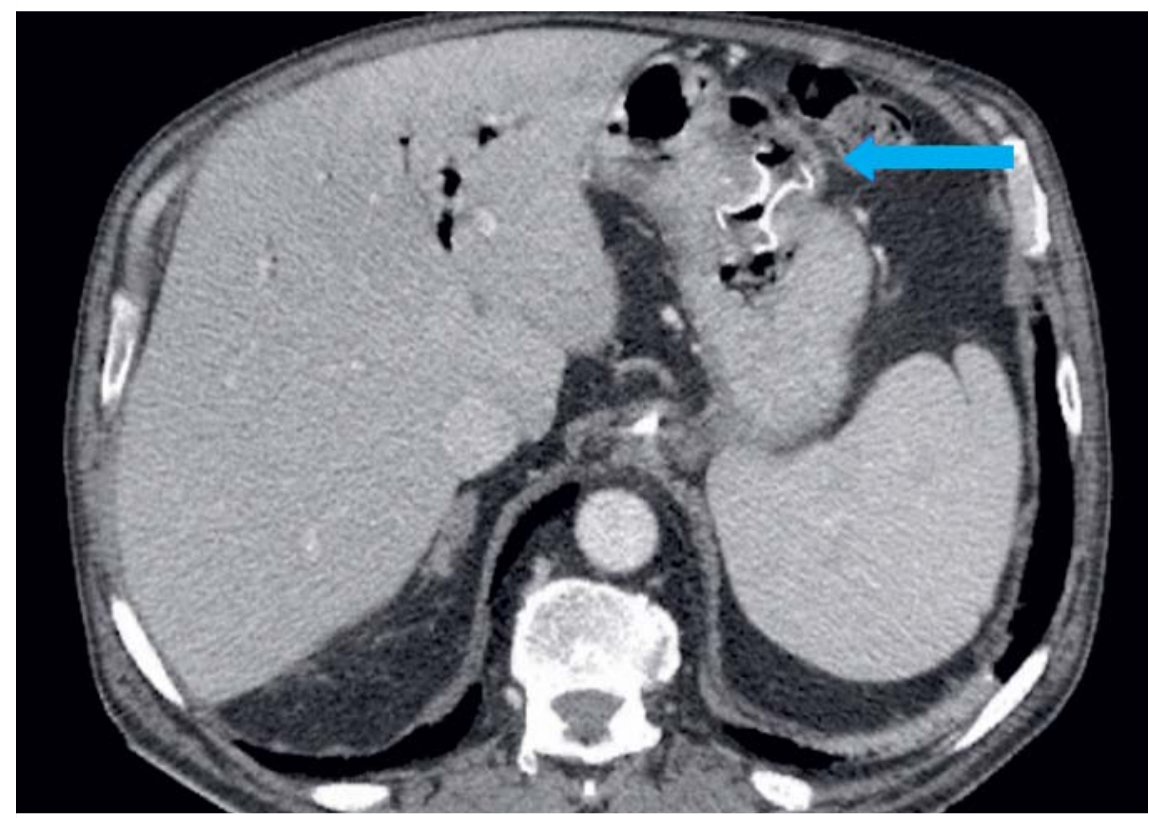

Fig. 1 Computed tomography scan confirming the correct positioning of the stent between the stomach and the abdominal abscess.

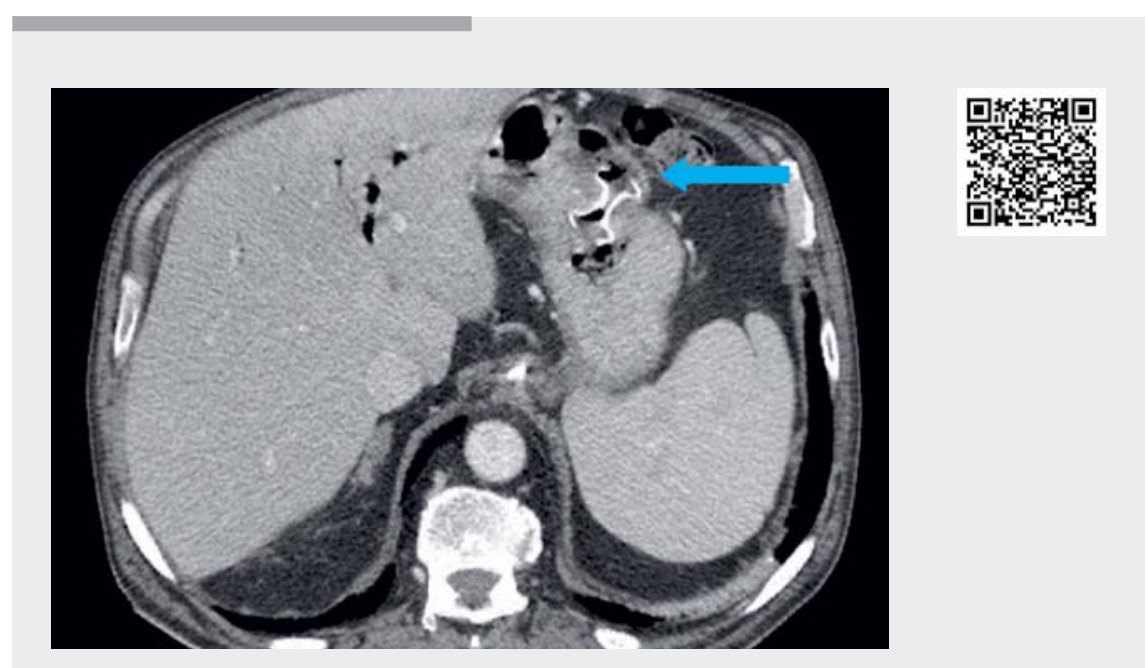

Video 1 Endoscopic ultrasound-guided transgastric drainage of an abdominal abscess is performed using a lumen-apposing metal stent. The stent is removed 10 days later, after resolution of the collection, and an over-the-scope clip is placed to close the gastric hole, with hemostasis being achieved with injection of tissue glue. 
after an injection of tissue glue (N-butyl cyanoacrylate methacryloxy sulfolane). The patient remained in a satisfactory clinical condition and he was discharged home the day after the procedure and referred back to recommence oncology treatment.

In conclusion, EUS-guided drainage of an abdominal abscess using a LAMS can be considered a minimally invasive technique. However, randomized controlled trials should be performed to compare this procedure with other available treatments (such as CT-guided or ultrasoundguided drainage, or surgery).

Endoscopy_UCTN_Code_TTT_1AS_2AC FB ok

\section{Competing interests}

The authors declare that they have no conflict of interest.
The authors

Mauro Manno, Simona Deiana, Laura

Ottaviani, Sara Vavassori, Tommaso Gabbani, Paola Soriani

Gastroenterology and Digestive Endoscopy Unit, Azienda USL Modena, Carpi Hospital, Carpi,

Modena, Italy

\section{Corresponding author}

\section{Mauro Manno, MD}

Gastroenterology and Digestive Endoscopy Unit, Azienda USL Modena, Carpi Hospital, Via G. Molinari 2, 41120 Carpi (MO), Italy

m.manno@ausl.mo.it

\section{References}

[1] Bang JY, Varadarajulu S. Lumen-apposing metal stents for endoscopic ultrasonography-guided interventions. Dig Endosc 2019; 31: 619-626

[2] Fernandez-Urien I, Elosua A, Bernad B et al. EUS-guided drainage of a pelvic abscess. VideoGIE 2019; 4: 274-275
Bibliography

DOI https://doi.org/10.1055/a-1073-7396

Published online: 20.12.2019

Endoscopy 2020; 52: E219-E220

(c) Georg Thieme Verlag KG

Stuttgart · New York

ISSN 0013-726X

\section{ENDOSCOPY E-VIDEOS \\ https://eref.thieme.de/e-videos}

回局 Endoscopy E-Videos is a free access online section, reporting 靣: on interesting cases and new techniques in gastroenterological endoscopy. All papers include a high quality video and all contributions are freely accessible online.

This section has its own submission website at

https://mc.manuscriptcentral.com/e-videos 